\title{
AVALIAÇÕES QUÍMICAS E BIOQUÍMICAS DOS GRÃOS, EXTRATOS E TOFUS DE SOJA COMUM E DE SOJA LIVRE DE LIPOXIGENASE ${ }^{1}$
}

\author{
Chemical and biochemical evaluation of grains, soymilk and tofus of normal soybean and \\ lipoxygenase-free soybeans
}

\author{
Sueli Ciabotti², Maria de Fátima Píccolo Barcellos ${ }^{3}$, \\ José Marcos Gontijo Mandarino 4 , Adriana Gadioli Tarone ${ }^{5}$
}

\begin{abstract}
RESUMO
Com este trabalho, objetivou-se avaliar a composição química e aspectos bioquímicos de soja comum, comum branqueada e livre de lipoxigenases e o efeito do processamento dos seus respectivos extratos de soja e tofus. A composição centesimal das cultivares de soja comum e livre de lipoxigenase não se diferenciaram ( $p>0,05)$. Alterações na composição centesimal e de minerais dos extratos de soja e dos tofus foram atribuídas ao tratamento térmico $\left(98^{\circ} \mathrm{C} / 5\right.$ minutos $)$ a que foi submetido o grão de soja comum e à etapa de maceração dos grãos, ficando evidente que algumas substâncias hidrossolúveis, foram migradas para a água de maceração dos grãos; o branqueamento na soja comum no início do processamento reduziu o teor de alguns minerais do extrato de soja (leite de soja), bem como no tofu. Ficou evidente as perdas de isoflavonas com o processamento na obtenção do tofu, na ordem de $38 \%$ no de SC, $31 \%$ no de SCB e 56\% no de SLL. O processamento térmico utilizado para obtenção dos tofus foi suficiente para eliminar a atividade dos inibidores de tripsina em $79 \%$ do tofu de soja comum, $81 \%$ no tofu de soja branqueada e $82 \%$ nos tofus de soja livre de lipoxigenase.
\end{abstract}

Termos para indexação: Extrato de soja e tofu, soja livre de lipoxigenase, composição centesimal, isoflavonas e inibidor de tripsina.

\begin{abstract}
The objective was to evaluate the chemical composition and biochemical aspects of normal, normal bleached and lipoxygenasefree soybean cultivars and the processing effect of the respective soymilk and tofu. Chemical composition of normal and lipoxygenasefree soybean cultivars did not differ $(\mathrm{p}>0.05)$. Changes in the chemical ascribed to the thermal treatment $\left(98^{\circ} \mathrm{C} / 5\right.$ minutes $)$ to which the normal soybean was submitted and to the grain soaking phase. In this phase it was evident that some hydrosoluble substances, leached to the grain maceration water, being that the bleaching of the normal soybean in the beginning of the processing reduced the content of some minerals in the soymilk and tofu. The soybean processing evidenced the losses of isoflavones in the tofu, in order of $38 \%$ in the normal soybean tofu, $31 \%$ in the bleached soybean tofu and $56 \%$ in lipoxygenase-free tofus. The thermal process used to obtain tofu was sufficient to eliminate the activity of the trypsin inhibitors by $79 \%$ in the normal soybean tofu, $81 \%$ in the bleached soybean tofu and $82 \%$ in lipoxygenase-free tofus.
\end{abstract}

Index terms: Soymilk e tofu, lipoxygenase-free soybeans, proximate composition, isoflavone, trypsin inhibitors.

(Recebido para publicação em 22 de setembro de 2004 e aprovado em 27 de dezembro de 2005)

\section{INTRODUÇÃO}

A soja [Glycine max (L.) Merrill.] e os seus produtos vêm sendo amplamente estudados devido não somente ao seu valor nutricional, mas também devido as suas propriedades funcionais na indústria de alimentos, e como alimento funcional, porque exerce ação moduladora em determinados mecanismos fisiológicos através de suas proteínas e isoflavonas.
O processamento do alimento pode proporcionar mudanças no seu teor de nutrientes e, conseqüentemente, na sua qualidade nutricional. No processamento da soja, a etapa de imersão dos grãos na água visando ao seu amaciamento é quase sempre necessária, e o tratamento térmico adequado da soja aumenta a digestibilidade de sua proteína, bem como inativa os inibidores de proteases e outros fatores antinutricionais. Vale salientar que o tratamento térmico das leguminosas é eficaz para inativar

\footnotetext{
${ }^{1}$ Parte da dissertação de Mestrado do primeiro autor apresentado à Universidade Federal de Lavras/UFLA - Caixa Postal 3037 - $37.200-000$ Lavras, MG.

2Mestre em Ciência dos Alimentos Universidade Federal de Lavras /UFLA - Professora do Centro Federal de Educação Tecnológica de Uberaba/ CETEC - sueliciabotti@terra.com.br

${ }^{3}$ Dra. em Ciência da Nutrição - Professora Adjunto do Departamento de Ciência dos Alimentos/DCA - Universidade Federal de Lavras/UFLA Caixa Postal 3037 - 37.200-000 - Lavras, MG.

${ }^{4}$ Pesquisador Embrapa-Soja - Londrina-PR.

${ }^{5}$ Graduanda em Engenharia de Alimentos - Departamento de Ciência dos Alimentos/DCA - Universidade Federal de Lavras/UFLA- Caixa Postal

3037 - 37.200-000 - Lavras, MG.
} 
substâncias antinutricionais, embora possa ocorrer atividade residual significativa de inibidores de proteases em produtos da soja, após tratamento térmico (BAYRAM et al., 2004).

Os produtos da soja sofrem restrições de consumo pela população em consequiência do sabor característico desagradável atribuído à ação das lipoxigenases em alguns ácidos graxos poliinsaturados (AXEROLD et al., 1981; DAVIES \& NIELSEN, 1986). Nelson et al. (1979) propuseram o processo de branqueamento dos grãos, visando a inativação dessas lipoxigenases.

A proteína nos grãos apresenta cerca de 30 a $45 \%$, sua composição porém é influenciada por fatores ambientais, genéticos, locação e safra, causando alterações no rendimento, na qualidade do extrato de soja e respectivo tofu (BHARDWAJ et al., 1999).

Pelo fato do tratamento térmico, ou seja por branqueamento, inativar a lipoxigenase e ainda por se ter o conhecimento da existência de cultivares de soja livre desta enzima, neste trabalho avaliou-se a composição química do grão de soja da cultivar comum (SC) e da livre de lipoxigenase (SLL), bem como do extrato de soja e dos respectivos tofus obtidos de SC, SC branqueada (SCB) e SLL.

\section{MATERIALE MÉTODOS}

O trabalho foi desenvolvido no Laboratório de Bioquímica Nutricional do Departamento de Ciência dos Alimentos da Universidade Federal de Lavras-MG.

As cultivares de soja comum BRS 133, e BRS - 213, livre de lipoxigenase - lipoxigenase I, lipoxigenase II e lipoxigenase III, safra 2003, foram cedidas pela Empresa Brasileira de Pesquisa Agropecuária - Embrapa-Soja - PR.

As determinações de isoflavonas dos grãos de soja e de seus respectivos tofus foram realizadas no Laboratório de Análises Cromatográficas da Embrapa-Soja-PR, por CLAE.

O fluxograma a seguir (Figura 1) apresenta os procedimentos gerais do trabalho.
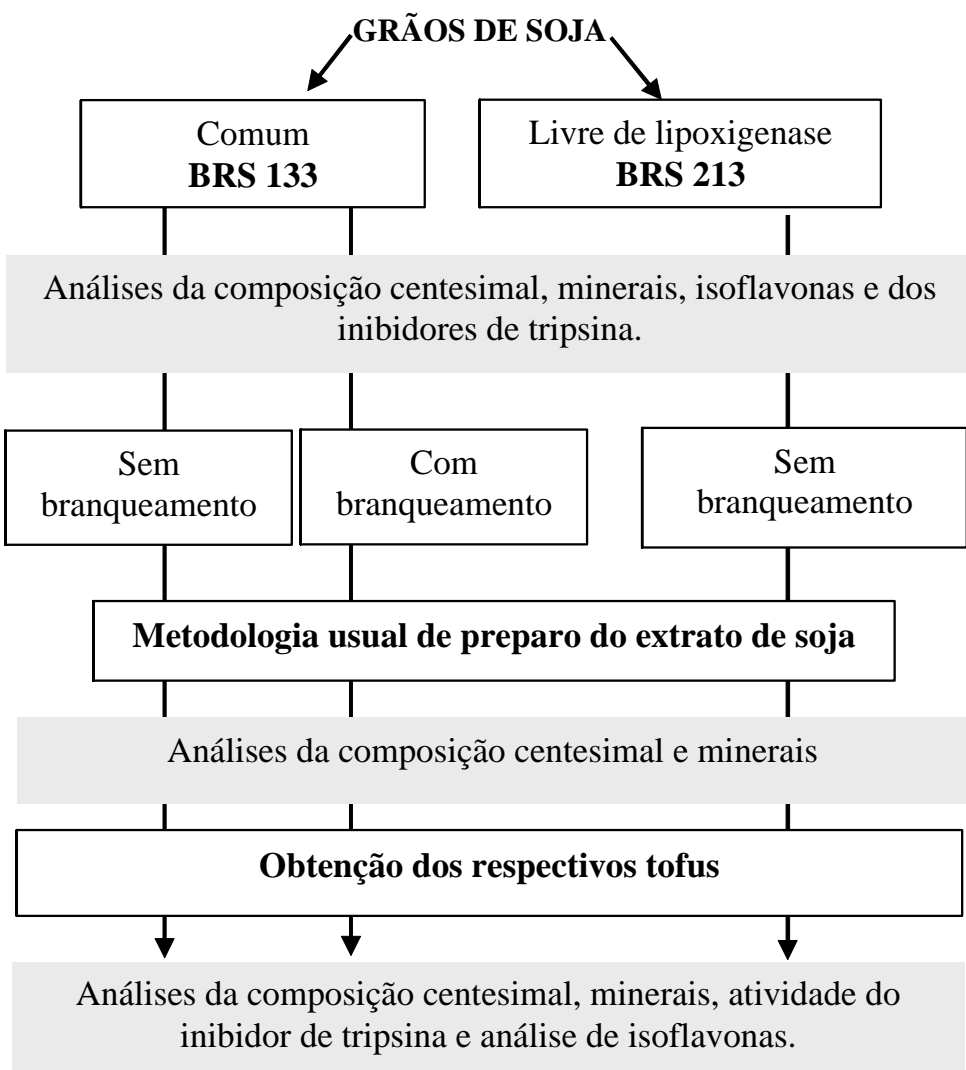

FIGURA 1 - Fluxograma geral da produção do extrato de soja e respectivos tofus e das análises químicas e bioquímicas realizadas. 


\section{Obtenção dos extratos de soja}

Inicialmente foram obtidos os extratos de soja (leite de soja, soymilk) originados de três tratamentos: soja comum (SC) pela metodologia usual, tratamento 1; soja comum branqueada (SCB) pela metodologia usual, porém com uma modificação no início do processo, onde os grãos foram submetidos ao branqueamento, tratamento 2; Soja livre de lipoxigenase (SLL) pela metodologia usual, ou seja, sem branqueamento tratamento 3 .

\section{Metodologia usual}

O método usual para a obtenção do extrato obedeceu a proporção de soja : água em 1:10, ou seja, 100 g de soja para 1 litro de água.

Após a pesagem, os grãos foram lavados e hidratados durante 12 horas à temperatura ambiente (aproximadamente $23^{\circ} \mathrm{C}$ ).

Após maceração e drenagem da água os grãos foram triturados, posteriormente a mistura foi filtrada, e o extrato foi submetido a aquecimento $\left(95\right.$ a $98^{\circ} \mathrm{C} / 10$ minutos $)$ e correção do volume final para $1 \mathrm{~L}$.

\section{Metodologia usual com branqueamento}

Antes de submeter ao processo de obtenção do extrato de soja pelo método usual, os grãos foram submetidos ao branqueamento utilizando água a $98^{\circ} \mathrm{C} / 5$ minutos e em seguidos resfriados.

\section{Obtenção do tofu}

Os extratos de soja a seguir foram resfriados até $75-80^{\circ} \mathrm{C}$ e, em $1 \mathrm{~L}$ de extrato adicionou-se 2,0 g de glucona-ä-lactona GDL, (Sigma Chemical, Louis, USA) diluído em $20 \mathrm{~mL}$ de água destilada, usado como agente coagulante para formação da coalhada, para obtenção do tofu. Após 10 minutos foram efetuados os cortes da coalhada e colocados em formas de polietileno com dessorador e prensado em torno de uma hora e meia com peso de $14 \mathrm{~g} / \mathrm{cm}^{2}$ e resfriado $\left(5^{\circ} \mathrm{C}\right.$ por 4 horas).

\section{Análises químicas e bioquímicas}

A avaliação da composição centesimal foi realizada para os grãos de soja, os extratos de soja e respectivos tofus, pelo método da AOAC (1990). A análise de gordura dos extratos de soja seguiu-se o método do lactobutirômetro de Gerber, segundo técnica descrita pelo IAL (1985). A fibra bruta foi determinada por gravimetria (KAMER \& GINKEL, 1952), e a fração glicídica foi obtida pelo cálculo da diferença.

As concentrações de $\mathrm{Ca}, \mathrm{Cu}, \mathrm{Zn}, \mathrm{P}, \mathrm{Fe}$ e $\mathrm{K}$ foram determinadas segundo Malavolta et al. (1989) e Sarruge \& Haag
(1974). Os extratos foram obtidos por digestão nitroperclórica. $\mathrm{O} \mathrm{P}$ foi determinado por colorimetria, segundo AOAC (1990); Ca, Cu, Zn e Fe por espectrometria de absorção atômica e $\mathrm{K}$ por fotometria de chama.

Para as análises de isoflavonas foi utilizada a metodologia adaptada de Berhow (2002) e Berhow et al. (2002), que teve como princípio a extração das isoflavonas em grãos e tofu. Os grãos de soja branqueados foram posteriormente liofilizados. Inicialmente desengorduraramse as amostras com n-hexano e após secagem, adicionouse solução extratora - $80 \%$ de metanol e $20 \%$ de dimetilsulfóxido (DMSO), a qual foi ultrasonicada e deixada em repouso, para posterior filtragem da amostra. As amostras foram injetadas seguindo os procedimentos usuais para Cromatografia líquida de alta eficiência - CLAE. Para quantificação das isoflavonas utilizou-se o sistema de gradiente binário, com fase móvel de acetonitrila e metanol, e temperatura de coluna a $26^{\circ} \mathrm{C}$.

A atividade do inibidor de tripsina nos grãos crus e no tofu foi determinada pelo ensaio enzimático de Kakade et al. (1974), utilizando como substrato, o benzoyl-DL-arginina p-nitroanilida (BAPNA), conforme escrita pela AACC (1976).

As análises estatísticas constaram de um delineamento experimental inteiramente casualizado com cinco repetições. Os efeitos de tratamentos foram comparados pelo teste $\mathrm{F}$ e em seguida analisados através da comparação de médias pelo teste de Scott \& Knott (1974) ao valor nominal de significância de $5 \%$. As análises de variância e teste de médias foram realizadas segundo técnicas usuais do software SISVAR (FERREIRA, 2000).

\section{RESULTADOS E DISCUSSÃO}

\section{Composição centesimal das cultivares de soja, extratos de soja e respectivos tofus}

$\mathrm{Na}$ Tabela 1, são apresentados os resultados médios da composição centesimal dos grãos da soja comum e da soja livre de lipoxigenase.

Verifica-se na Tabela 1 que, o conteúdo de proteína e lipídeos da soja livre de lipoxigenase não foi diferente do teor protéico da soja convencional.

A composição química das cultivares de soja em estudo se mostra de acordo com os valores encontrados por Cai et al. (1997) e Smith \& Circle (1978). As cultivares analisadas neste trabalho apresentaram diferença significativa $(\mathrm{p}<0,05)$ apenas no teor de umidade.

$\mathrm{Na}$ Tabela 2, são apresentados os resultados da composição centesimal dos extratos de soja produzidos com SC, SCB e SLL. 
TABELA 1 - Valores médios da composição centesimal (\%) dos grãos das cultivares de soja comum (SC) e de soja livre de lipoxigenase* (SLL).

\begin{tabular}{ccccccc}
\hline Cultivares & Umidade & Proteína* $^{*}$ & Lipídios & Cinzas & Fibra & ENN $^{\mathbf{1}}$ \\
\hline SC & $9,59 \mathrm{a}$ & $32,77 \mathrm{a}$ & $15,74 \mathrm{a}$ & $3,64 \mathrm{a}$ & $7,56 \mathrm{a}$ & $30,09 \mathrm{a}$ \\
SLL & $9,28 \mathrm{~b}$ & $33,29 \mathrm{a}$ & $15,30 \mathrm{a}$ & $3,84 \mathrm{a}$ & $7,09 \mathrm{a}$ & $31,19 \mathrm{a}$ \\
\hline EP** & 0,054 & 0,211 & 0,175 & 0,157 & 0,184 & 0,264 \\
\hline
\end{tabular}

Médias nas colunas seguidas por letras iguais não diferem entre si ao nível de significância de 0,05 pelo Teste F.

**Erro padrão da média.

Dados expressos com base em matéria integral.

$*$ Proteína $=\%$ N X 6,25

${ }^{1} \mathrm{ENN}=$ extrato não nitrogenado.

TABELA 2 - Valores médios da composição centesimal (\%) dos extratos de soja obtidos de soja comum (SC), soja comum branqueada (SCB) e soja livre de lipoxigenase (SLL).

\begin{tabular}{cccccc}
\hline Extrato de soja & Umidade & Proteína* $^{*}$ & Lipídios & Cinzas & ENN $^{\mathbf{1}}$ \\
\hline SC & $93,70 \mathrm{~b}$ & $3,56 \mathrm{a}$ & $1,62 \mathrm{~b}$ & $0,30 \mathrm{~b}$ & $0,81 \mathrm{a}$ \\
SCB & $95,18 \mathrm{a}$ & $3,12 \mathrm{~b}$ & $1,48 \mathrm{c}$ & $0,18 \mathrm{c}$ & $0,05 \mathrm{~b}$ \\
SLL & $93,79 \mathrm{~b}$ & $3,26 \mathrm{~b}$ & $1,72 \mathrm{a}$ & $0,36 \mathrm{a}$ & $0,87 \mathrm{a}$ \\
\hline EP** & 0,117 & 0,090 & 0,014 & 0,014 & 0,101 \\
\hline
\end{tabular}

Médias nas colunas seguidas por letras iguais não diferem entre si ao nível de significância de 0,05 (Scott-Knott).

**Erro padrão da média.

Dados expressos com base em matéria integral.

$*$ Proteína $=\%$ N X 6,25

${ }^{1} \mathrm{ENN}=$ extrato não nitrogenado.

Na Tabela 2, demonstra-se que o teor de proteína do extrato de soja obtido da cultivar de soja comum, SC é maior pelo método tradicional de obtenção do extrato de soja em relação ao teor protéico do extrato de soja obtido da mesma cultivar após o processo de branqueamento (98 ${ }^{\circ} \mathrm{C} / 5$ minutos), visando inativar as lipoxigenases, porém é importante observar o teor protéico do extrato de SCB foi igual $(p>0,05)$ ao teor protéico da SLL, valendo salientar que o extrato de soja obtido da soja livre de lipoxigenase, não foi submetido ao branqueamento.

A umidade do extrato de soja comum branqueada diferenciou significativamente $(\mathrm{p}<0,05)$ da soja comum e livre de lipoxigenase e o teor de proteína $(3,12)$ apresentou diferença significativa da soja comum $(3,56 \%)$, indicando que o branqueamento seguido de maceração interferindo na solubilização das proteínas aumentou o teor de água, assim como a maceração influenciou na quantidade extraída de proteína, cinzas e extrato não nitrogenado, na água de maceração. Iwuoha \& Umunnakwe (1997) observaram perdas de proteínas na obtenção de extrato de soja em que os grãos sofreram o branqueamento.

Rosenthal et al. (2002), trabalhando com cultivar de soja especialmente desenvolvida para alimentação humana, verificaram no extrato de soja teores de $2,86 \%$ de proteína, $1,53 \%$ de gordura, $0,27 \%$ de cinzas, $93,81 \%$ de umidade e $1,53 \%$ de carboidratos (calculados por diferença), valores aproximados aos encontrados neste trabalho.

$\mathrm{Na}$ Tabela 3 é apresentada a composição centesimal dos tofus produzidos com SC, SCB e SLL. O tofu obtido de SCB apresentou teores mais elevados de proteínas $(p<0,05)$ que os tofu obtidos da SC sem o branqueamento e da SLL. O tofu obtido da soja livre de lipoxigenase teve o teor de 
proteína mais elevado do que a soja convencional salientando que os grãos não foram submetidos ao processo de branqueamento.

O branqueamento do grão de soja comum em água, realizado na etapa inicial da obtenção do extrato de soja para obtenção do respectivo tofu, proporcionou condições mais adequadas de extração das proteínas. Esta diferença no teor de proteína do tofu obtido de soja comum (SC) e soja comum branqueada (SCB) também pode ser explicada pela reação dos derivados da oxidação dos ácidos graxos pela lipoxigenase, reações que criam ligações com proteínas, deixando estas mais desnaturadas, menos solúveis e menos expostas ao processo de lixiviação. As maiores perdas de cinzas no tofu de soja comum branqueada, provavelmente foram devidas a migração de sais durante o tratamento térmico (branqueamento) seguido de maceração, ressaltando que as sojas utilizadas para obtenção do tofu de SC e SLL foram adicionadas diretamente na água sem serem submetidas ao branqueamento. Resultados encontrados em outros trabalhos onde a soja é submetida ao calor no processo de maceração ficam mais expostos a perdas de componentes químicos dentre eles os minerais (BAYRAM et al., 2004; WANG et al., 1979).

A composição centesimal dos tofus analisados se equivale aos teores encontrados por Fukushima (1980) que foram de: $88 \%$ de umidade, $6 \%$ de proteína, $3,5 \%$ de extrato etéreo, $0,6 \%$ de cinzas, $1,9 \%$ de carboidratos.

\section{Composição de minerais}

As concentrações de fósforo, potássio, cálcio, cobre, zinco e ferro das cultivares de soja comum (SC) e da cultivar livre de lipoxigenase (SLL) se encontram expressas na Tabela 4. Pode-se notar diferenças significativas $(\mathrm{p}<0,05)$ nos teores de potássio, cálcio, cobre e ferro, o que representam influências genéticas e ambientais que interferem nestas variações (BHARDWAJ et al., 1999).

Comparando-se os valores destes minerais, com os apresentados na revisão de Smith \& Circle (1978) a composição de soja para cálcio 0,16 a $0,47 \%$, fósforo 0,42 a $0,82 \%$, zinco $37 \mathrm{mg} / \mathrm{kg}$ e para cobre $12 \mathrm{mg} / \mathrm{kg}$, respectivamente, valores próximos aos encontrados neste trabalho.

Em comparações de ferro total das cultivares Tókio $(80,98 \mathrm{mg} / \mathrm{kg})$ e Jackson $(81,54 \mathrm{mg} / \mathrm{kg})$ analisadas por Beard et al. (1996) em matéria seca, aproxima-se dos valores encontrados neste trabalho que foram de 79,93 (SC) e 86,97 $\mathrm{mg} / \mathrm{kg}$ (SLL) considerando base seca, já que a média de umidade destas sementes foram de 9,60 e 9,28, respectivamente.

Em estudos de Riet et al. (1989), foram verificados em três cultivares de soja teores de potássio de 1,609 a $1,739 \%$, valores próximos aos aqui relatados para as cultivares comum e livre de lipoxigenase.

$\mathrm{Na}$ Tabela 5, são apresentados os teores médios de fósforo, potássio, cálcio, cobre, zinco e ferro do extrato de soja obtidos de SC, SCB e SLL.

TABELA 3 - Valores médios da composição centesimal (\%) dos tofus produzidos com soja comum (SC), soja comum branqueada (SCB) e soja livre de lipoxigenase (SLL).

\begin{tabular}{cccccc}
\hline Tofus & Umidade & Proteína* $^{*}$ & Lipídios & Cinzas & ENN $^{\mathbf{1}}$ \\
\hline SC & $82,82 \mathrm{a}$ & $9,19 \mathrm{c}$ & $5,65 \mathrm{a}$ & $0,86 \mathrm{a}$ & $1,46 \mathrm{a}$ \\
SCB & $82,42 \mathrm{a}$ & $9,84 \mathrm{a}$ & $5,98 \mathrm{a}$ & $0,76 \mathrm{~b}$ & $0,99 \mathrm{a}$ \\
SLL & $83,49 \mathrm{a}$ & $9,54 \mathrm{~b}$ & $4,97 \mathrm{~b}$ & $0,76 \mathrm{~b}$ & $1,23 \mathrm{a}$ \\
\hline EP** & 0,272 & 0,091 & 0,126 & 0,029 & 0,215 \\
\hline
\end{tabular}

Médias nas colunas seguidas por letras iguais não diferem entre si ao nível de significância de 0,05 (Scott-Knott).

**Erro padrão da média.

Dados expressos com base em matéria integral.

$*$ Proteína $=\%$ N X 6,25

${ }^{1} \mathrm{ENN}=$ extrato não nitrogenado.

Ciênc. agrotec., Lavras, v. 30, n. 5, p. 920-929, set./out., 2006 
TABELA 4-Teores médios de minerais de soja comum (SC) e de soja livre de lipoxigenase (SLL).

\begin{tabular}{|c|c|c|c|c|c|c|}
\hline \multirow{2}{*}{ Cultivares } & $\mathbf{P}$ & $\mathbf{K}$ & Ca & $\mathbf{C u}$ & Zn & $\mathbf{F e}$ \\
\hline & \multicolumn{3}{|c|}{$(\%)$} & \multicolumn{3}{|c|}{$\mathrm{mg} / \mathrm{kg}$} \\
\hline SC & $0,664 \mathrm{a}$ & $1,696 \mathrm{~b}$ & $0,170 \mathrm{a}$ & $12,200 \mathrm{a}$ & $44,160 \mathrm{a}$ & $72,266 \mathrm{~b}$ \\
\hline SLL & $0,655 \mathrm{a}$ & $1,895 \mathrm{a}$ & $0,155 \mathrm{~b}$ & $9,575 \mathrm{~b}$ & $44,645 \mathrm{a}$ & $78,900 \mathrm{a}$ \\
\hline $\mathrm{EP}^{* * *}$ & 0,010 & 0,011 & 0,005 & 0,297 & 0,550 & 0,942 \\
\hline
\end{tabular}

Médias nas colunas seguidas por letras iguais não diferem entre si ao nível de significância de 0,05 (Teste F).

**Erro padrão da média.

Dados expressos com base em matéria integral.

TABELA 5 - Teores médios de minerais de extrato de soja obtidos da: soja comum (SC), soja comum branqueada (SCB) e soja livre de lipoxigenase (SLL).

\begin{tabular}{|c|c|c|c|c|c|}
\hline \multirow{2}{*}{ Extrato de soja } & $\mathbf{P}$ & $\mathbf{K}$ & $\mathrm{Cu}$ & $\mathbf{Z n}$ & $\mathbf{F e}$ \\
\hline & \multicolumn{2}{|c|}{$(\%)$} & \multicolumn{3}{|c|}{$\mathrm{mg} / \mathrm{kg}$} \\
\hline $\mathrm{SC}$ & $0,074 \mathrm{~b}$ & $0,142 \mathrm{a}$ & $1,816 \mathrm{a}$ & $4,592 \mathrm{a}$ & $12,700 \mathrm{a}$ \\
\hline SCB & $0,062 \mathrm{~b}$ & $0,080 \mathrm{~b}$ & $1,216 \mathrm{c}$ & $2,978 \mathrm{c}$ & $7,900 \mathrm{~b}$ \\
\hline SLL & $0,093 \mathrm{a}$ & $0,143 \mathrm{a}$ & $1,505 \mathrm{~b}$ & $4,203 \mathrm{~b}$ & $13,038 \mathrm{a}$ \\
\hline $\mathrm{EP}^{* *}$ & 0,014 & 0,014 & 0,024 & 0,346 & 0,427 \\
\hline
\end{tabular}

Médias nas colunas seguidas por letras iguais não diferem entre si ao nível de significância de 0,05 (Scott-Knott).

**Erro padrão da média.

Dados expressos com base em matéria integral.

Pode-se observar que o tratamento térmico na soja comum branqueada influenciou $(\mathrm{p}<0,05)$ os teores de potássio, cálcio, cobre, zinco e ferro nos extratos de soja. Fato este que se deve provavelmente à migração destes componentes para a água de maceração dos grãos (BAYRAM et al., 2004; BYUN et al., 1996).

Byun et al. (1996) encontraram teores de potássio, fósforo, cálcio e magnésio em maiores quantidades na água de maceração, no tempo de 16 horas de hidratação em temperatura de $20^{\circ} \mathrm{C}$, o que implica dizer que a etapa de maceração contribuiu para a redução dos teores de minerais.

Os teores de ferro dos extratos de soja encontrados no presente trabalho foram de $1,27 \mathrm{mg}$ na SC; $0,79 \mathrm{mg}$ na $\mathrm{SCB}$ e 1,3 mg na SLL em $100 \mathrm{~g}$ de extrato, ficando evidente as perdas ocorridas de ferro no processo de branqueamento seguido de maceração dos grãos de soja para obtenção do extrato. Liener (1978) informa que o teor de ferro do extrato de soja é de $6,8 \mathrm{mg}$ de ferro/100 g do extrato, porém, Soyafood.Info (2004) relata conteúdo de ferro do extrato de soja de $0,58 \mathrm{mg}$ de ferro/100g. Essas referências não descrevem o teor de minerais da soja utilizada para obtenção do extrato, nem mesmo a proporção soja : água.

Soyafood.Info (2004) relata valores de potássio de $141 \mathrm{mg} / 100 \mathrm{~g}$ de extrato de soja; de cobre $0,12 \mathrm{mg} / 100 \mathrm{~g}$ de extrato e de zinco $0,23 \mathrm{mg} / 100 \mathrm{~g}$ de extrato. Comparando estes valores com os respectivos minerais dos extratos de soja verificados no presente trabalho, nota-se que apenas o zinco da SC e da SLL encontra-se bastante elevado.

Os teores médios de fósforo, potássio, cálcio, cobre, zinco e ferro de tofus obtidos de SC, SCB e SLL encontram-se na Tabela 6.

Nos tofus obtidos de soja comum branqueada observa-se que os teores de potássio $(0,072 \%)$, cálcio $(0,070 \%)$ e ferro $(11,846 \mathrm{mg} / \mathrm{kg})$ estão significativamente mais baixos, que os valores verificados nos tofus de soja comum e livre de lipoxigenase, provavelmente pelas perdas destes minerais na etapa do branqueamento seguido de maceração. Por outro lado, houve uma concentração de zinco $(9,01 \mathrm{mg} / \mathrm{kg})$ superior aos tofus de soja comum $(7,29$ $\mathrm{mg} / \mathrm{kg})$ e de soja livre de lipoxigenase $(8,07 \mathrm{mg} / \mathrm{kg})$, devido provavelmente à ligação deste mineral com outras substâncias na coagulação do tofu. 
TABELA 6 - Teores médios de minerais de tofus obtidos da: soja comum (SC), soja comum branqueada (SCB) e soja livre de lipoxigenase (SLL).

\begin{tabular}{cccccccc}
\hline \multirow{2}{*}{ Tofu } & $\mathbf{P}$ & $\mathbf{K}$ & $\mathbf{C a}$ & & $\mathbf{C u}$ & $\mathbf{Z n}$ & $\mathbf{F e}$ \\
\cline { 2 - 4 } \cline { 6 - 8 } & \multicolumn{9}{c}{$\mathbf{( \% )}$} & & & $\mathbf{m g} / \mathbf{k g}$ & \\
\hline SC & $0,094 \mathrm{a}$ & $0,118 \mathrm{a}$ & $0,088 \mathrm{a}$ & & $2,048 \mathrm{a}$ & $7,29 \mathrm{c}$ & $12,968 \mathrm{a}$ \\
SCB & $0,090 \mathrm{a}$ & $0,072 \mathrm{~b}$ & $0,070 \mathrm{~b}$ & & $2,248 \mathrm{a}$ & $9,01 \mathrm{a}$ & $11,846 \mathrm{~b}$ \\
SLL & $0,090 \mathrm{a}$ & $0,130 \mathrm{a}$ & $0,080 \mathrm{a}$ & & $2,173 \mathrm{a}$ & $8,075 \mathrm{~b}$ & $12,100 \mathrm{~b}$ \\
\hline EP** & 0,002 & 0,004 & 0,005 & & 0,047 & 0,155 & 0,278 \\
\hline
\end{tabular}

Médias nas colunas seguidas por letras iguais não diferem entre si ao nível de significância de 0,05 (Scott Knott).

**Erro padrão da média.

Dados expressos com base em matéria integral.

Soyafood.Info (2004) cita valores de minerais no tofu de: $147 \mathrm{mg}$ fósforo, 176 potássio, 162 cálcio, 0,24 cobre, 1 zinco e $1,45 \mathrm{mg}$ ferro em $100 \mathrm{~g}$ de tofu. Comparando com os minerais dos tofus do presente trabalho, constata-se que apenas para o cálcio, os teores citados do presente trabalho encontram-se muito abaixo, provavelmente Soyafood.Info (2004) tenha usado para a fabricação do tofu coagulante a base de cálcio.

\section{Análises de isoflavonas}

Na Tabela 7 são mostrados os valores médios de isoflavonas da soja comum (SC), soja comum branqueada (SCB) e de soja livre de lipoxigenase (SLL) e dos respectivos tofus.

A soja comum apresentou o total médio de isoflavonas de $174,51 \mathrm{mg} / 100 \mathrm{~g}$, a soja comum branqueada $145,97 \mathrm{mg} / 100 \mathrm{~g}$ e a soja livre de lipoxigenase de $220,21 \mathrm{mg} /$ $100 \mathrm{~g}$. Valores médios foram relatados por Carrão-Panizzi et al. (1999) em cultivares da região Sul do Brasil entre 86,3 $\mathrm{mg} / 100 \mathrm{~g}$ e $218,7 \mathrm{mg} / 100 \mathrm{~g}$. Portanto estes teores estão praticamente dentro desta faixa.

Pode-se observar as perdas ocorridas na composição de isoflavonas do tofu, comparadas com o grão de soja comum e ao grão de soja comum branqueado de $38 \%$ e $31 \%$, respectivamente. Isto pode ser explicado pelo processo de maceração, moagem, tratamento térmico e coagulação do tofu. Já a soja livre de lipoxigenase apresentou perdas de isoflavonas de 56\% na produção do tofu, quando comparada com o grão. Jackson et al. (2002) mostraram perdas nos totais de isoflavonas de $36 \%$ na produção do tofu, em relação às quantidades presentes na soja crua.

As formas de malonil-conjugadas foram especialmente desestabilizadas pelo processamento. Os níveis de isoflavonas agliconas, genisteína e daidzeína aumentaram devido ao processamento. Os teores de malonil daidzina e malonil genistina reduziram, devido à clivagem dos grupos ésteres malonil para as formas daidzina e genistina sob moagem dos grãos e o calor a que foi submetido o extrato. Resultados semelhantes foram relatados por Jackson et al. (2002).

Pode-se observar que ocorreram perdas de aproximadamente $16,3 \%$ nas quantidades de isoflavonas totais nos grãos de soja comum como resultado do branqueamento comparado com o mesmo grão sem o branqueamento, o que provavelmente se explica pelo próprio tratamento térmico do grão, seguido de extração na água de maceração. Jackson et al. (2002) encontraram $4 \%$ de perdas de isoflavonas totais na água de maceração dos grãos, $31 \%$ no resíduo do extrato e $18 \%$ no soro extraído do tofu.

\section{Análises de inibidores de tripsina dos grãos de soja e dos tofus}

Na Tabela 8 são apresentados os valores médios da atividade do inibidor de tripsina da soja comum (SC), soja livre de lipoxigenase (SLL) e dos tofus obtidos com SC, SCB e SLL, expressos em unidades de tripsina inibidas (UTI) por mg de amostra seca e desengordurada (UTI/mg).

Os valores observados nas cultivares de soja crua mostram que a soja comum diferiu significativamente $(p<0,05)$ da soja livre de lipoxigenase com valores de 36,58 e 45,26 UTI/mg, respectivamente. Resultados semelhantes foram encontrados por Miura et al. (2001), de 43,06 UTI/mg.

Considerando a atividade de inibidor de tripsina inicial das amostras de soja, observa-se que o tratamento térmico dado ao tofu de soja comum eliminou $79 \%$ da atividade inibidora de tripsina e a soma do calor do branqueamento da soja comum e mais o tratamento térmico do extrato de soja para obtenção do tofu, eliminou $81 \%$ e os tofus produzidos com o grão livre de lipoxigenase apresentaram $82 \%$ de inibição. 
TABELA 7 - Valores médios (mg/100 g de matéria seca) das isoflavonas do grão de soja comum (SC), soja comum branqueada (SCB) e de soja livre de lipoxigenase (SLL) e dos respectivos tofus e porcentagens de perdas de isoflavonas com a produção do tofu.

\begin{tabular}{|c|c|c|c|c|c|c|c|}
\hline \multirow{2}{*}{\multicolumn{2}{|c|}{ Isoflavonas }} & \multicolumn{2}{|c|}{ SC } & \multicolumn{2}{|c|}{$\mathrm{SCB}$} & \multicolumn{2}{|c|}{ SLL } \\
\hline & & grão & tofu & grão & tofu & grão & tofu \\
\hline \multirow{3}{*}{$\beta$-glicosídeos } & Daidzina & 34,48 & 15,24 & 25,02 & 8,38 & 38,84 & 11,55 \\
\hline & Glicitina & 11,20 & 4,43 & 8,67 & 2,89 & 24,33 & 4,53 \\
\hline & Genistina & 30,01 & 20,71 & 24,81 & 15,35 & 33,36 & 20,05 \\
\hline \multicolumn{2}{|c|}{ Sub-total } & 75,69 & 40,38 & 58,50 & 26,62 & 96,53 & 36,13 \\
\hline \multirow{3}{*}{$\begin{array}{c}\text { Malonil } \\
\beta \text {-glicosídeos }\end{array}$} & Daidzina & 41,23 & 23,15 & 38,81 & 21,01 & 51,14 & 18,28 \\
\hline & Glicitina & 0,00 & 0,00 & 0,00 & 0,00 & 25,00 & 0,00 \\
\hline & Genistina & 42,71 & 26,51 & 41,81 & 28,12 & 43,17 & 25,32 \\
\hline \multicolumn{2}{|c|}{ Sub-total } & 83,94 & 49,66 & 80,62 & 49,13 & 119,31 & 43,60 \\
\hline \multirow{3}{*}{$\begin{array}{l}\text { Acetil-1- } \beta- \\
\text { glicosídeos }\end{array}$} & Daidzina & 5,47 & 0,00 & 0,00 & 0,00 & 0,00 & 0,00 \\
\hline & Glicitina & 0,00 & 0,00 & 0,00 & 0,00 & 0,00 & 0,00 \\
\hline & Genistina & 8,19 & 0,00 & 0,00 & 0,00 & 0,00 & 0,00 \\
\hline \multicolumn{2}{|c|}{ Sub-total } & 13,66 & 0,00 & 0,00 & 0,00 & 0,00 & 0,00 \\
\hline \multirow{3}{*}{ Agliconas } & Daidzeína & 0,00 & 8,70 & 3,93 & 12,82 & 2,43 & 7,14 \\
\hline & Gliciteína & 0,00 & 1,65 & 0,00 & 1,85 & 0,00 & 1,03 \\
\hline & Genisteína & 1,22 & 8,29 & 2,92 & 9,61 & 1,94 & 9,71 \\
\hline \multicolumn{2}{|c|}{ Sub-total } & 1,22 & 18,64 & 6,85 & 24,28 & 4,37 & 17,88 \\
\hline \multicolumn{2}{|c|}{ Total } & 174,51 & 108,69 & 145,97 & 100,67 & 220,21 & 97,61 \\
\hline \multicolumn{2}{|c|}{$\%$ total } & 100 & 62 & 100 & 69 & 100 & 44 \\
\hline \multicolumn{2}{|c|}{$\%$ perdas na obtenção do tofu } & \multicolumn{2}{|c|}{38} & \multicolumn{2}{|c|}{31} & \multicolumn{2}{|c|}{56} \\
\hline
\end{tabular}

TABELA 8 - Valores médios da atividade do inibidor de tripsina dos grãos das cultivares de soja comum e soja livre de lipoxigenase e dos respectivos tofus e porcentagens de eliminação do inibidor de tripsina.

\begin{tabular}{cccc}
\hline \multirow{2}{*}{ Cultivares } & \multicolumn{2}{c}{ UTI*/mg de amostra seca e desengordurada } & $\begin{array}{c}\text { Eliminação do inibidor de tripsina } \\
\text { na obtenção do tofu (\%) }\end{array}$ \\
\cline { 2 - 3 } & Grãos $^{\mathbf{1}}$ & Tofu $^{\mathbf{2}}$ & 79 \\
SC & $36,58 \mathrm{~b}$ & $7,74 \mathrm{a}$ & 81 \\
$\mathrm{SCB}$ & - & $7,09 \mathrm{~b}$ & 82 \\
\hline SLL & $45,26 \mathrm{a}$ & $8,07 \mathrm{a}$ & - \\
\hline EP** & 0,718 & 0,172 &
\end{tabular}

Médias nas colunas seguidas por letras iguais não diferem entre si ao nível de significância de 0,05 (Scott Knott).

*UTI = unidade de tripsina inibida

**Erro padrão da média.

1 = extração do inibidor por 1 hora; 2 = extração do inibidor por 3 horas.

Sabe-se que o calor intenso para destruição do inibidor de proteína não é necessário, pois, diminui a taxa de eficiência protéica, conseqüentemente a perda do valor nutricional e alterações nas propriedades funcionais da soja. A maioria dos produtos comerciais de soja retém 5 a $20 \%$ da atividade inibitória original (LIENER, 1994). 


\section{CONCLUSÕES}

A composição dos macronutrientes foi semelhante em ambas cultivares de soja estudadas: a comum e livre de lipoxigenase.

O branqueamento da soja comum realizado no início do processamento reduziu o teor de alguns minerais $(\mathrm{P}$, $\mathrm{Cu}, \mathrm{Zn}$ e $\mathrm{Fe}$ ) do extrato de soja (leite de soja), bem como no conteúdo de minerais do tofu.

Durante a obtenção dos tofus, as perdas de isoflavonas foram mais marcantes na cultivar livre de lipoxigenase do que na cultivar comum.

O processamento térmico utilizado para obtenção dos tofus foi suficiente para eliminar $79 \%$ da atividade inibidora de tripsina no tofu de soja comum, $81 \%$ no tofu de soja branqueada e $82 \%$ no tofu de soja livre de lipoxigenase.

\section{REFERÊNCIAS BIBLIOGRÁFICAS}

AMERICAN ASSOCIATION OF CEREAL CHEMISTS. Approved methods of the American Association of Cereal Chemists. 9. ed. Saint Paul, 1976.

ASSOCIATION OF OFFICIAL ANALYTICAL CHEMISTS. Official methods of analytical of the Association of Official Analytical Chemists. 15. ed. Washington, 1990. v. 2.

AXEROLD, B.; CHEESEBROUGH, T. M.; LAAKSSO, S. Lipoxygenase from soybeans. Methods Enzymology, Oxford, v. 71, p. 441-451, 1981.

BAYRAM, M.; KAYA, A.; ONER, M. D. Changes in properties of soaking water during production of soybulgur. Journal of Food Engineering, Oxford, v. 61, n. 2, p. 221-230, Feb. 2004.

BEARD, J. L.; BURTON, J. W.; THEIL, E. C. Purified ferritin and soybean meal can be sources of iron for treating iron deficiency in rats. Journal of Nutrition, Bethesda, v. 126, n. 1, p. 154-160, Jan. 1996.

BERHOW, M. A. Modern analytical techniques for flavonoid determination. In: BUSLIG, B. S.; MANTHEY, J. A. (Eds.). Flavonoids in the living cell. New York: Kluwer Academic, 2002. p. 61-76.

BERHOW, M. A.; CANTRELL, C. L.; DUVAL, S. M.; DOBRINS, T. A.; MAYNES, J.; VAUGHN, S. F. Analysis and quantitative determination of group B saponins in processed soybean products. Phytochemical Analysis, Sussex, v. 13, n. 6, p. 343-348, Nov./Dec. 2002.

BHARDWAJ, H. L.; BHAGSARI, A. S.; JOSHI, J. M.; RANGAPPA, M.; SAPRA, V. T.; RAO, M. S. S. Yield and quality of soymilk and tofu made from soybean genotypes grown at four locations. Crop Science, Madison, v. 39, n. 2, p. 401-405, Mar./Apr. 1999.

BYUN, M. W.; KANG, I. J.; MORI, T. Effect of $y$-irradiation on the water soluble components of soybean. Radiation Physics Chemistry, Oxford, v. 47, n. 1, p. 155-160, Jan. 1996.

CAI, T. D.; CHANG, K. C.; SHIH, M. C.; HOU, H. J.; JI, M. Comparison of bench and production scala methods for making soymilk and tofu from 13 soybean varieties. Food Research Internacional, Amsterdam, v. 30, n. 9, p. 659-668, Sept. 1977.

CARRÃO-PANIZZI, M. C.; BELÉIA, A. D. P.; PRUDÊNCIOFERREIRA, S. H.; OLIVEIRA, M. C. N.; KITAMURA, K. Effects of isoflavones on beany flavor and adstringency of soymilk and cooked wholo soybean grains. Pesquisa Agropecuária Brasileira, Brasília, v. 34, n. 6, p. 1045-1052, jun. 1999.

DAVIES, C. S.; NIELSEN, N. C. Genetic analysis of a nullallele for lipoxygenase: 2 in soybeans. Crop Sciense, Madison, v. 26, n. 3, p. 460-436, May/June 1986.

FERREIRA, D. F. Análise estatística por meio do SISVAR para Windows versão 4.0. In: REUNIAO ANUAL DA REGIÃO BRASILEIRA DA SOCIEDADE INTERNACIONAL DE BIOMETRIA, 45., 2000, São Carlos. Anais... São Carlos: UFSCar, 2000. p. 255-258.

FUKUSHIMA, D. Deterioratie changes of proteins during soybean food processing and their use in foods. In: WITAKER, J. R.; FUJIMAKI, M. Chemical deterioration of proteins. Washington: American Chemical Society, 1980. cap. 10 , p. $211-239$.

INSTITUTO ADOLFO LUTZ. Normas analíticas do instituto Adolfo Lutz: métodos químicos e físicos para análise de alimentos. 3. ed. São Paulo, 1985. v. 1, 533 p.

IWUOHA, C. I.; UMUNNAKWE, K. E. Chemical, physical and sensory characteristics of soymilk as affected by processing method, temperature and duration of stocage. Food Chemistry, Oxford, v. 59, n. 3, p. 373-379, July 1997. 
JACKSON, C.; DINI, J. P.; RUPASINGHE, H. P. V.; FAULKNER, H.; POYSA, V.; BUZZELL, D.; DEGRANDIS, $S$. Effects of processing on the content and composition of isoflavones during manufacturing of soy beverage and tofu. Process Biochemistry, Oxford, v. 37, n. 10, p. 1117 1123, May 2002.

KAKADE, M. L.; RACKIS, J. J.; McGHEE, J. E.; PUSKI, G. Determination of trypsin inhibitor activity of soy products: a collaborative analysis of an improved procedure. Cereal Chemistry, Saint Paul, v. 51, n. 3, p. 376-388, May/June 1974.

KAMER, J. H. van der; GINKEL, L. van. Rapid determination of crude fiber in cereals.

Cereal Chemistry, Saint Paul, v. 29, n. 4, p. 239-251, July 1952.

LIENER, I. E. Implications of antinutritional components in soybean foods. Critical Reviews in Food Sciense and Nutrition, Boca Raton, v. 34, n. 1, p. 31-67, Jan. 1994.

LIENER, I. E. Nutricional value of protein products. In: SWITH, A. K.; CIRCLE, S. J.

Soybeans: chemistry and tecnology. Westport: The Avi, 1978. v. 1, p. 470.

MALAVAOLTA, E.; VITTI, G. C.; OLIVEIRA, S. A.Avaliação de estado nutricional de plantas. Piracicaba: Potafos, 1989. 201 p.

MIURA, E. M. Y.; BINITTI, M. A. R.; CAMARGO, D. S.; MIZUBITO, I. Y.; IDA, E. I. Avaliação biológica de soja com baixas atividades de inibidores de tripsina e ausência do inibidor Kunitz. Archivos Latinoamericanos de Nutricion, Caracas, v. 51, n. 2, p. 195-198, jun. 2001.
NELSON, A. I.; WEI, S. L.; STEINBERG, M. P. Foods from whole soybeans. In: WORD SOYBEAN RESEARCH CONFERENCE, 2., 1979, Corbinn. Proceedings... Corbin: Westview, 1979. p. 745-761.

RIET, W. B. van der; WIGHT, A. W.; CILLIERS, J. J. L.; DATEL, J. M. Food chemical investigation of tofu and its byproduct okara. Food Chemistry, Oxford, v. 34, n. 3, p. 193-202, 1989.

ROSENTHAL, A.; DELIZA, R.; CABRAL, L. M. C.; CABRAL, L. C.; FARIAS, C. A. A.; DOMINGUES, A. M. Effect of enzymatic treatment and filtration on sensory characteristics and physical stability of soymilk. Food Control, Oxford, v. 14, n. 3, p. 187-192, Apr. 2002.

SARRUGE, J. R. R.; HAAG, H. P. Análise química em plantas. Piracicaba: ESALQ/USP, 1974. 56 p.

SCOTT, A. J.; KNOTT, M. A. A cluster analysis method for grouping meams in the analysis of variance. Biometrics, Washington, v. 30, n. 3, p. 507-512, Sept. 1974.

SMITH, A. K.; CIRCLE, S. J. Soybeans: chemistry and tecnology. Westport: The Avi, 1978. v. 1, p. 470.

SOYAFOOD.INFO. Nutritional values of soybeans, soymilk, tofu et tempeh. Disponível em: <http:// Lwww.soya.be/nutritional-values-of-soybeans.php> Acesso em: 10 fev. 2004.

WANG, H. L.; SWAIN, E. W.; HESSELTINE, C. W.; HEAT, H. D. Hydratation of wole soybean affects solids losses and cooking quality. Journal of Food Science, Chicago, v. 44, n. 5, p. 1510-1513, Sept./Oct. 1979. 